\title{
Energy Efficient Technology for Solid Waste Management in IoT-Enabled Smart City
}

\author{
S. M. Turkane, Mayur D. Mhase, C. B. Kadu, P. S. Vikhe
}

\begin{abstract}
The issues related to the solid and solvable waste generation and its management has become a serious concern in both the rural and urban areas, as there is a lot of migration of people from rural area to urban area which had leads the population of that area increased to few folds. Due to large human population, the solid waste had also increased and thus the management of this solid waste is now a major challenge. Nowadays Internet of Things (IOT) has evolved as a promising Technology to solve the issues of solid waste management in smart city. IOT consist of Smart devices viz. Sensors, Global System for Modulation (GSM) and Global Positioning System (GPS) technology which are incorporated in the atmosphere to monitor and collect information. In our work we have implemented the efficient technology for solid waste management in IOT environment. IOT enabled waste bin monitoring and its location to transportation department through web link is provided for information in the Control room. The solid waste is then recycled at recycling centers and updates of this recycled material (compost) is sent to control room so we used it as fertilizer for soil.
\end{abstract}

Keywords: Internet of Things, Smart Cities, Waste Management, Internet Communication Technology.

\section{INTRODUCTION}

The populations in smart cities increases day by day and due to this requirement of basic services for keeping the city hygienically clean also increases. Solid waste management is one of the essential tasks in smart cities (SC) [1]. The Web advancements upgraded by the utilization of the Web Convention (IP) and various remote sensors empower the Web of Things (IOT) environment [2]. Number of sensors has the chance to be a piece of Remote Sensor Systems (WSNs). Right when WSNs are associated in a city, they are responsible for gathering and preparing encompassing information and hence to redesign inheritance city foundation supposed Keen Urban communities (SCs) [8]. This meaning of SC shows the central part of a savvy situation which is

Manuscript published on November 30, 2019.

* Correspondence Author

S. M. Turkane*, E\&TC Engineering, Pravara Rural Engineering College, Loni, India. Email: satish_turkane@yahoo.co.in

Mayur D Mhase, E\&TC Engineering, Pravara Rural Engineering College, Loni, India. Email: mayurmhase4282@gmail.com

C. B. Kadu, Instrumentation \& Control Engineering, Pravara Rural Engineering College, Loni, India. Email: chandrakant kadu@yahoo.com

P. S. Vikhe, Instrumentation \& Control Engineering, Pravara Rural Engineering College, Loni, India. Email: pratap.vikhe@gmail.com

(C) The Authors. Published by Blue Eyes Intelligence Engineering and Sciences Publication (BEIESP). This is an open access article under the CC-BY-NC-ND license

(http://creativecommons.org/licenses/by-nc-nd/4.0/) basically embraced for frameworks managing environmental pollution. In this paper our objective is development of efficient solid waste management system. The management of solid waste has direct impact on environment and life of the people living in city. It is basic to productively deal with the waste arranged in each area of a SC concentrating on the gathering exercises as well as on its transport and reusing.

We model the waste management as a lot of administrations over an IOT foundation in a SC. These administrations spread the accompanying pieces of a waste management conspires (i) Waste gathering preparation and implementation ((ii) Transport of waste to specific location (iii) Recycling and preparation for Re-use. This system consists of waste level monitoring, collection and recycling at recycling centers. Several devices are adopted for efficient implementation of waste collection e.g., Sensor, GPS, GSM, Web link. These devices give a smart transportation system that outcomes progressively headings gave to the accumulation of waste bin. In particular, we present a far reaching model on the Information and Communication Technologies (ICT) in waste management models concentrating on the modern ICT tools and technologies [10]. We developed a model using python programing which is the most used programming tool in today's era.

\section{RELETED WORK}

C. Balakrishna et al, [1] proposed that Internet is very useful platform for connecting the smart devices like sensors and RFID technology, every object in environment could be connected that would yield tremendous human efficiency. The people in smart city use different types of smart devices such as information accumulation sensors, IP camera to supply data which is utilized to oversee resources and assets productively. The smart city idea incorporates information and communication technology (ICT), and different physical devices such as sensors, cameras, GPS, RFID connected to the network (IOT) to optimize the efficiency of city operation what's more, administrations and interface with residents. Smart city innovation permits city authorities and individuals living in city to collaborate straightforwardly with both network and city foundation and to screen what's going on in the city and how the city is advancing.

A. Vakali et al, [2] proposed that Smart cities are nowadays expanding worldwide with smart things like sensors and actuators, and cell phones applications and establishments which change the whole structure of city. 


\section{Energy Efficient Technology for Solid Waste Management in IoT-Enabled Smart City}

Their work consisted of collecting the information from various locations, processing that control information and all other operation smartly with fast Internet communication technology. The EADIC consist of implementation of particular needs of the most different forms of smart cities, for these purpose ICT are used.

M.A.Mamun et al [3] proposed Solid waste canister observing framework utilizing remote sensor organize which can give current update about waste insight the bins using ZigBee and GSM/GPRS technologies and wireless Sensors. With the rapid growth rate of population of Municipal Solid Waste is (MSW) is up flooding step by step and it is winding up progressively hard dealing with the MSW.

B. Chowdhury et al, [4] proposed the utilization of RFID (Radio Frequency Identification) and load cell sensor and gas sensor innovation is utilized for waste management in keen city to encourage robotizing waste (e.g., garbage, recycling, and green) distinguishing proof and weight Measurement forms for structuring brilliant IOT based waste administration frameworks. This paper diagrams the RFID and sensor model utilized for creating RFID and sensor based Real-time waste administration frameworks. RFID-based waste administration framework predominantly comprises of a solid waste (RFID) tag, a Reader and a waste administration IT framework.

M. Faccio et al, [5] proposed multi target directing model with constant information exchange for the private waste accumulation, in light of the reconciliation of new mechanical detectability frameworks with another heuristic routing model. The constant detectability information sources of info are gotten by the recognizability innovation gadgets introduced and are in respect to the powerful substitution of bin and vehicles, visited bin and vehicles position.

A Rovetta et al, [6] suggested that gathered waste is as of now sent to landfills or to burning plants inside the setting explored, the significant truth to be considered in waste accumulation systems incorporate observing of the general measure of waste created, quantitative estimation of the waste present at every collection point and recognizable proof of classes of material present in the collected waste. The framework displayed here may establish an appropriate instrument, meeting necessities, for example, (i) The estimation of delivered waste for arranging and accountancy reasons, (ii) The early location of dangerous materials with the point of preventing harm to plants (iii) Estimation of waste substance to help the presentation of waste arranging.

G Suciu et al, [7] analyzed the usability of the Cloud and IoT ideas with regards to Smart City organization. Since the early instantiations/usage of the two advancements, it has turned out to be obvious that their combination could prompt a scope of multiplicative advantages. Most IoT applications involve countless heterogeneous geologically disseminated sensors.

Furthermore, cloud foundations could help the computational limits of IoT applications, given that few multi-sensor applications need to perform complex handling that is liable to timing (and different QoS imperatives). Contingent upon the sort of figuring assets conveyed by means of the cloud, cloud administrations take various structures, for example, Network as a Service (NaaS),
Infrastructure as an administration (IaaS), Platform as an administration (PaaS), Software as an administration (SaaS), Cloud processing and IoT are along these lines two basic advances for understanding the universal interchanges vision.

A. Paukov et al, [15] In this examination, the establishments have been created for a low-temperature, ecologically safe technique for effective handling of natural city strong waste, which might be additionally connected for handling together metropolitan and mechanical waste organics so as to get fluid items.

Municipal solid waste(MSW), the measure of which has expanded essentially over the previous decades, incorporates food waste, paper, plastics, wood, glass, calfskin, elastic, material, yard trimmings, and others materials. Handling of strong waste can be completed by organic and thermal techniques. Natural strategies are utilized for the preparing of food, plant, and paper waste.

\section{Methodology}

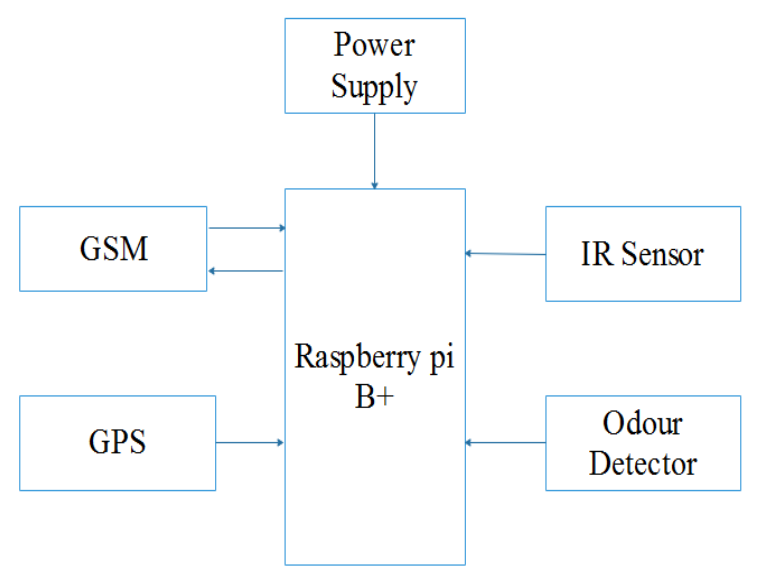

Fig.1.Block Diagram of Solid Waste Management

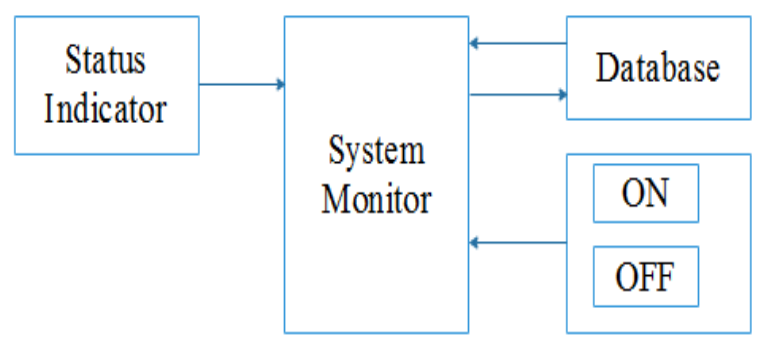

Fig.2.Block Diagram of IOT Section

Block diagram schematic of System and IOT of the proposed methodology are as given in the above Figure 1 . The proposed plan centers around research approaches that utilization presents day ICT methods and instruments in SCs. We center on the idea of waste administration setting that expects to arrangement the reason for ordering waste administration models. The waste administration framework comprises of equipment, apparatuses, information and programming which give the answer for waste. As a rule, the waste administration did three principle stages: (i) Physical foundation, (ii) IOT Technology, and (iii) Software examination. 
In the proposed methodology the raspberry pi is used to Control the overall circuit and also two sensors are used the IR sensor as well as odor sensor used. The speed of Processor speed ranges from $700 \mathrm{MHz}$ to $1.4 \mathrm{GHz}$ for the Pi 3 Model $\mathrm{B}+$; On-board memory ranges from $256 \mathrm{MB}$ to 1 GB RAM. Secure Digital (SD) cards in Micro SDHC structure facto are utilized to store the working framework and program memory, IR sensor used to monitoring the waste in the bin. The level of the garbage bin and location is sent to the control room and smart phone with the help of web link and IOT module on continuous time basis. Odor sensor is used for detecting the odor in recycling process so we can send the update about recycling of waste to control room. Figure 2 shows the block diagram of IOT section which consists of:

\section{A. Status Indicator}

It consists of IOT webpage which shows the values of the IR sensor in the garbage bin. The level of the waste collected in the garbage bin and compost status is indicated in the status indicator of the IOT Section (PC).

\section{B. System Monitoring (PC)}

This system monitoring block consist of a computer system for monitoring and controlling the entire system of the smart waste management using IOT and it is usually a personal computer.

\section{Database}

Database is the block where all the information is stored and it can be easily accessed by the system monitoring block as given above.

\section{RESULTS AND ANALYSIS}

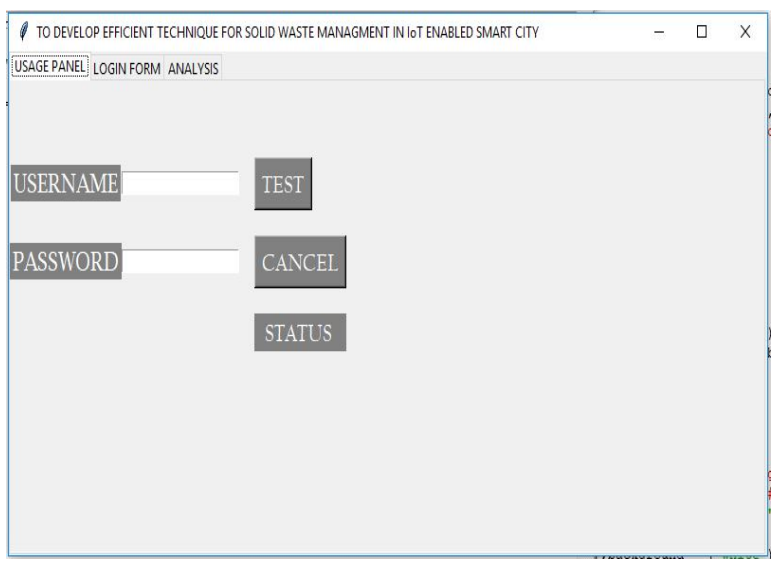

Fig. 3.Usage Panel

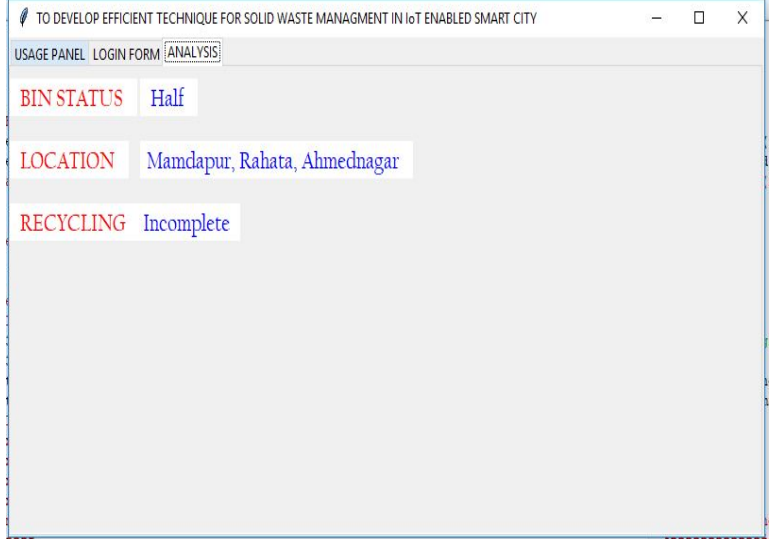

Fig. 4.Status of Bin

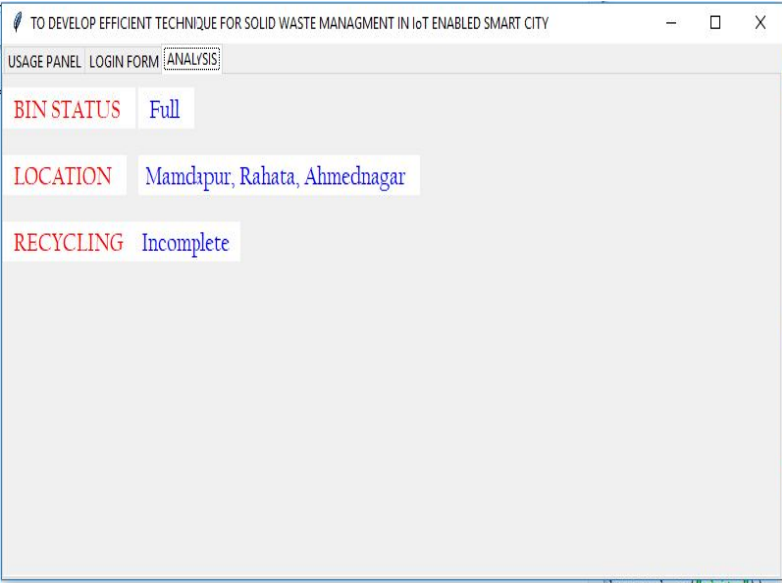

Fig. 5.Status of Bin

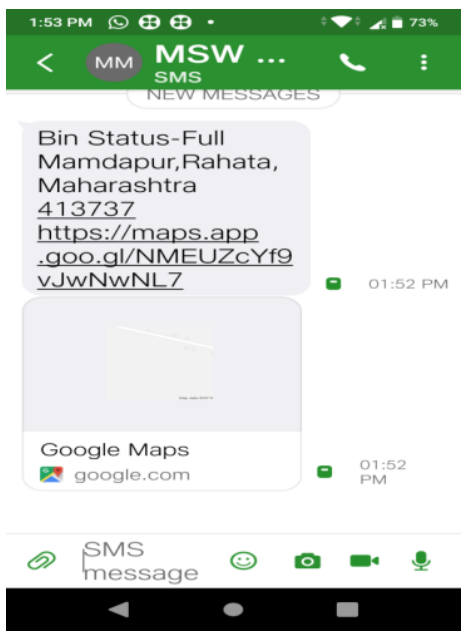

Fig. 6.Messaging System

1. Solid waste management gives the update about waste on web page. We have to login with username and password as shown in figure 4 and figure 5 this web page gives the information about waste bin full and half level. It also gives the location of bin where it is full. It also gives the update about the recycling.

2. Also implemented the massaging system using GSM shown in figure 6 which sends the massage directly to truck driver which include status of the bin and location link of bin so that driver finds the route to reach the bin location.

Published By: 


\section{Energy Efficient Technology for Solid Waste Management in IoT-Enabled Smart City}

\section{Conclusion}

This paper represents an intellectual solid waste management system. The arrangement is based on IOT model. It gives the location of waste bin which is full. It is responsible for measuring the waste level in the waste bins and later sends this information through internet. We also implement the system for recycling of the solid waste as early as possible and update of recycled material send to control room. We also implemented the massaging system using GSM which sends the massage directly to truck driver which include status of the bin and location link of bin. In general there is improvement in waste management in smart city by using internet communication technology.

At long last, our future work is centered around the meaning of a compelling IoT-empowered model for solid waste collection, which gives update about the waste on web page. However as the part of future work we are looking to add direction link in web page which also sent to messaging system so that truck driver can easily find shortest path to bin location.

\section{REFERENCES}

1. C. Balakrishna, "Enabling Technologies for Smart City Services and Applications", IEEE 6th International Conference on Next Generation Mobile Applications, Services and Technologies (NGMAST), 2012, pp. 775-780.

2. A Vakali, L. Anthopoulos, and S. Krco, "Smart Cities Data Streams Integration: experimenting with Internet of Things and social data flows", In the Proceedings of the 4th ACM International Conference on Web Intelligence, Mining and Semantics (WIMS'14), 2014, pp. 1-5.

3. M. A. Mamun, M. A. Hannan, A. Hussain, and H. Basri, "Wireless Sensor Network Prototype for Solid Waste Bin Monitoring with Energy Efficient Sensing Algorithm", IEEE International Conference on Computational Science and Engineering (CSE), 2013, pp. 382-387.

4. B. Chowdhury, and M. U. Chowdhury, "RFID-based real-time smart waste management system", IEEE Australasian Conference on Telecommunication Networks and Applications (ATNAC), 2007, pp. 175-180.

5. M. Faccio, A. Persona, and G. Zanin, "Waste collection multi objective model with real time traceability data", Waste Collection, vol. 31 (12), 2011, pp. 2391-2405.

6. A. Rovetta, F. Xiumin, F. Vicentini, M. Zhu, A. Giusti, and Q. He, "Early detection and evaluation of waste through sensorized containers for a collection monitoring application", Waste Collection, vol. 29 (12), 2009, pp. 2939-2949.

7. G. Suciu, A. Vulpe, S. Halunga, O. Fratu, G. Todoran, and V. Suciu, "Smart Cities Built on Resilient Cloud Computing and Secure Internet of Things", IEEE 19th International Conference on Control Systems and Computer Science (CSCS), 2013, pp.513-518.

8. Centre of Regional Science, "Smart Cities. Ranking of European Medium-Sized Cities", Vienna University of Technology, 2007, http://www.smart-cities [Accessed on: May 1, 2019].

9. D. Nirmala, Geetha Bala, S. Kaviya, S. Pavithra, "Smart Waste Management Using Internet-Of Things (IOT)", College of Engineering and Technology, Chennai 600048.

10. Kostas kolomvatsos, Alexey Medvedev, Pouria Amirian, Jeremy Morley, Stathes Hadjieftymiades" Challenges and Opportunities of Waste Management in IOT-enabled Smart Cities: A Survey ". IEEE 2016, PP. 2377-3782.

11. J. Jin, J. Gubbi, S. Marusic, and M. Palaniswami, "An Information Framework for Creating a Smart City Through Internet of Things", Internet of Things Journal, vol. 1 (2), 2014, pp. 223-229.

12. G. Suciu, A. Vulpe, S. Halunga, O. Fratu, G. Todoran, and V. Suciu, "Smart Cities Built on Resilient Cloud Computing and Secure Internet of Things", IEEE 19th International Conference on Control Systems and Computer Science (CSCS), 2013, pp. 513-518.

13. B. Zhou, C. Sun, H. Yi (2017, Dec 3).Solid Waste Disposal in Chinese Cities:An Evaluation of Local Performance. Sustainability 2017, 9, 2234, pp.1-20. Available:http://www.mdpi.com

14. K. M. Keramitsoglou and K. P. Tsagarakis (2018, Apr 18).Public Participation in Designing the Recycling Bins to Encourage Recycling .Sustainability 2018,10,1240,pp.1-17.Available:http://www.mdpi.com
15. A. Paukov, R. Magaril and E.Magaril (2019, Jan 10).An Investigation of the Feasibility of the Organic Municipal Solid Waste Processing by Cooking. Sustainability 2019, 11, 389, pp.1-13. Available: http://www.mdpi.com

\section{AUTHORS PROFILE}

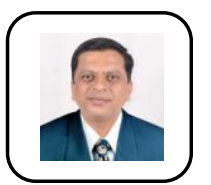

Satish M. Turkane received the Ph.D degree in Electronics \& Telecommunication Engineering from Savitribai Phule Pune University, Pune in 2018. He completed his Bachelors and Masters in Electroncis \& Telecommunication Engineering from DNPCOE, Shahada and SSGMCOE, Shegaon respectively.He is working in the capacity of Associate Professor and Head of Electronics \& Telecommunication Engineering at Pravara Rural Engineering College Loni, Ahmednagar affiliated to Savitribai Phule Pune University, Pune.

He has more than 19 Years of teaching experience. He had contributed his research work by publishing more than 26 research articles at national, International journals, IEEE Conferences, International Conferences etc. He had also published 1 book in the area of multi user FPGA. His area of interest is in the field of Low power FPGA, Interconnects and Post CMOS Devices and Circuits in Analog and Digital domain. He is a Life Member of ISTE, IEI and IETE.

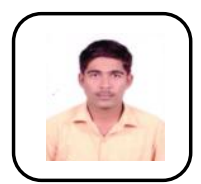

Mayur D. Mhase had completed his Bachelor's Degree in Electronics \& Telecommunication from Pravara Rural Engineering College, Loni, Ahmednagar affiliated to Savitribai Phule Pune University, Pune. He is currently pursuing his Master's Degree in Embedded and VLSI from Pravara Rural Engineering College, Loni.

His area of interest is in the field of Image Processing, Embedded Systems and IOT.

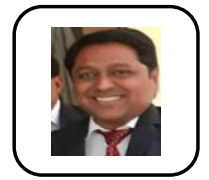

Chandrakant B. Kadu received the $\mathrm{Ph}$. D degree in Instrumentation and Control Engineering from College of Engineering, Pune (COEP) affiliated to Savitribai Phule Pune University in 2018. He has completed his Bachelors and Masters in Instrumentation and Control Engineering from Pravara Rural Engineering College, Loni affiliated to Savitribai Phule Pune University in 1998 and 2005 respectively. He works as an Associate Professor and Head in the Department of Instrumentation and Control Engineering, at Pravara Rural Engineering College, Loni, District Ahmednagar affiliated to Savitribai Phule Pune University, Pune. His research interests include control systems, sliding mode control and process control. He is an author of more than 40 research papers published at national, conference proceedings. He is a life member of ISTE, ISOI, and IAENG.

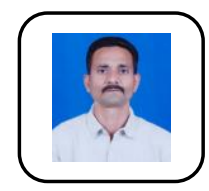

P. S. Vikhe received the M. Tech and Ph. D degree in Instrumentation engineering from SGGS Institute of Engineering and Technology, Nanded affiliated to Swami Ramanand Teerth Marathwada University, Nanded in 2009 and 2019 respectively. He had completed his Bachhelor's degree in Instrumentation Engineering from PDVVP, Ahmednagar affilaited to Savitribai Phule Pune University, Pune. He works as Associate Professor in the Department of Instrumentation and Control Engineering at Pravara Rural Engineering College, Loni, Ahmednagar affiliated to Savitribai Phule Pune Univeristy, Pune.

His research intrests include biomedical signal and image processing. Hi is author of few research papers published at national and international journals, conference proceedings. He is a life members of ISTE and IAENG. 